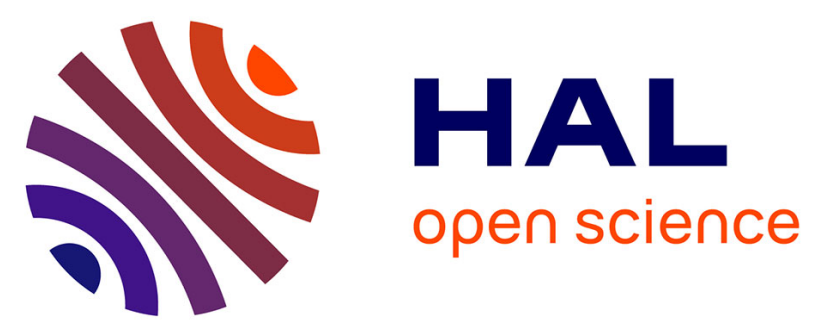

\title{
Consequences of spinal ankylosis on bone trabecular fragility assessed on CT scans in patients with ankylosing spondylitis. A retrospective study
}

Marine Fauny, Caroline Morizot, Edem Allado, Frank Verhoeven, Eliane Albuisson, Marie Semaan, Astrid Pinzano, Isabelle Chary-Valckenaere, Damien Loeuille

\section{To cite this version:}

Marine Fauny, Caroline Morizot, Edem Allado, Frank Verhoeven, Eliane Albuisson, et al.. Consequences of spinal ankylosis on bone trabecular fragility assessed on CT scans in patients with ankylosing spondylitis. A retrospective study. Joint Bone Spine, 2020, 87 (6), pp.625-631. 10.1016/j.jbspin.2020.05.009 . hal-02897934

\section{HAL Id: hal-02897934 \\ https://hal.science/hal-02897934}

Submitted on 30 Nov 2020

HAL is a multi-disciplinary open access archive for the deposit and dissemination of scientific research documents, whether they are published or not. The documents may come from teaching and research institutions in France or abroad, or from public or private research centers.
L'archive ouverte pluridisciplinaire HAL, est destinée au dépôt et à la diffusion de documents scientifiques de niveau recherche, publiés ou non, émanant des établissements d'enseignement et de recherche français ou étrangers, des laboratoires publics ou privés. 


\title{
Evaluation of bone trabecular density on CT scans according to the severity of spinal ankylosis in ankylosing spondylitis patients
}

Marine Fauny ${ }^{1,2}$, Caroline Morizot $^{1}$, Edem Allado ${ }^{1,3,4}$, Frank Verhoeven ${ }^{5}$, Eliane Albuisson ${ }^{6,7,8}$, Marie Semaan ${ }^{9,10}$, Astrid Pinzano 9,10 , Isabelle CharyValckenaere $^{1,9}$, Damien Loeuille ${ }^{1,9}$

\author{
${ }^{1}$ Department of Rheumatology, Nancy University Hospital, France \\ ${ }^{2}$ Saint Charles Hospital, 54200 Toul, France \\ ${ }^{3}$ Department of Pulmonary Function Testing and Exercise Physiology, Nancy University Hospital, F-54000. Nancy, France \\ ${ }^{4}$ Development, Adaptation and Disadvantage. Cardiorespiratory regulations and motor control (EA 3450 DevAH), University \\ of Lorraine, F-54505, France \\ ${ }^{5}$ Department of Rheumatology, Besançon University Hospital, France \\ ${ }^{6}$ Université de Lorraine, Faculté de Medecine, InSciDens, F-54000 Nancy, France \\ ${ }^{7}$ Université de Lorraine, CNRS, IECL, F-54000 Nancy, France \\ ${ }^{8}$ CHRU-Nancy, DRCI, Département MPI, Unité de méthodologie, Data management et statistiques UMDS, F-54000 Nancy, \\ France \\ ${ }^{9}$ Ingénierie Moléculaire et Physiopathologie Articulaire (IMoPA). UMR 7365 CNRS - University of Lorraine, France \\ ${ }^{10}$ Contrat d'Interface, Department of Rheumatology, Nancy University Hospital, France
}

\section{Corresponding author:}

Marine Fauny

Rheumatology Department (Pr Chary-Valckenaere)

University Hospital of Nancy, 54511 VANDOEUVRE LES NANCY

FRANCE

m.fauny@chru-nancy.fr

$+33383153203$

M. Fauny: m.fauny@chru-nancy.fr

C. Morizot : c.morizot@chru-nancy.fr

E. Allado : e.allado@chru-nancy.fr

F. Verhoeven : fverhoeven@,chu-besancon.fr

E. Albuisson : e.albuisson@chru-nancy.fr
M. Semaan : marie.semaan@balamand.edu.lb

A. Pinzano : astrid.pinzano@univ-lorraine.fr

I. Chary-Valckenaere : i.valckenaere@chru-nancy.fr

D. Loeuille : d.loeuille@chru-nancy.fr 


\section{Abstract}

Background: Ankylosing spondylitis (AS) patients seems to be at risk of osteoporosis but bone screening is not often performed. The objective was to evaluate the effect of vertebral ankylosis on scanographic bone attenuation coefficient (SBAC) on lumbar vertebrae in AS patients.

Patients and methods: This study included AS patients fulfilling New York criteria who underwent both thoraco-abdomino-pelvic computed tomography and X-rays during routine follow-up. The modified stoke ankylosing spondylitis spinal score (mSASSS) was scored on $\mathrm{X}$-rays, and the presence of at least one syndesmophyte (mSASSS $\geq 2$ ) defined mSASSS+ patients. Ankylosis of a lumbar vertebra was defined by the presence of bone bridges to its two adjacent vertebrae. The SBAC was measured from L1 to L5, and the fracture threshold was set at $\mathrm{SBAC} \leq 145 \mathrm{HU}$.

Results: A total of 73 AS patients were included (mean age: 60.3 ( \pm 10.7$)$ years, 65 men $(89 \%)$ ). Sixty patients $(82.2 \%)$ were mSASSS+; 13 patients $(17.8 \%)$ presented ankylosis of at least one lumbar vertebra. The SBAC of each lumbar vertebra was not significantly different between mSASSS- and mSASSS+ patients. The SBAC was lower for patients with at least one bone bridge than for patients without $(\mathrm{p}<0.05)$. Patients with lumbar vertebral ankylosis had a higher risk of presenting an $\mathrm{SBAC} \leq 145 \mathrm{HU}$ (OR: 4.95 (95\% CI: 1.1-17.4)).

Conclusion: The presence of a bone bridge and complete ankylosis of lumbar vertebra were associated with a higher risk of SBAC under the fracture threshold, suggesting structural deterioration of trabecular bone in ankylosed vertebrae in AS patients.

Key words: Ankylosing spondylitis, osteoporosis, vertebral fracture, bone mineral density, CT scan, bone attenuation coefficient, ankylosis, mSASSS 


\section{Introduction}

Ankylosing spondylitis (AS) is an inflammatory rheumatic disease that mostly affects young adults. The symptomatology often concerns the axial skeleton and, less frequently, the peripheral skeleton (hands, feet) and the enthesis, with night pain and a prolonged morning stiffness. The pathophysiology of bone formation (syndesmophytes, enthesophytes, bone bridges) is complex [1,2] and coexists with bone resorption (bone erosion, osteoporosis). Due to this bone resorption, the prevalence of vertebral fracture (VF) and of its neurological complications is increased in the AS population (odds ratio 3.26) [3]. AS patients have a higher risk of osteoporosis, with a prevalence varying from 11.7 to $34.4 \%$ (14 to $27 \%$ in the spine and 4 to $14 \%$ in the hip) $[4,5,6,7,8,9,10]$. A significant bone loss was reported in $51 \%$ of patients with early spondyloarthritis at either lumbar spine or hip [11]. Osteoporosis could be explained by less general mechanical stress secondary to stiffness or ankylosis, coupled with reduced local mobility at the ankylosed disco-vertebral units $[10,12,13,14,15,16,17]$.

Dual X-ray absorptiometry (DXA) is considered the gold standard for the diagnosis of osteoporosis. In AS patients, bone mineral density on spine DXA can be overestimated due to the presence of new bone formation (syndesmophytes, bone bridge), especially with respect to anteroposterior incidence $[16,17,18,19,20]$.

Thoracic or thoraco-abdomino-pelvic computed tomography scans (CT scans), are often performed in AS patient follow-up to explore extra-articular comorbidities, therapeutic adverse events or before immunosuppressive drug initiation. Spine CT scans can also be performed to evaluate acute back pain in the ankylosed spine. Trabecular bone density evaluation is available on CT scans through the scanographic bone attenuation coefficient (SBAC) of lumbar vertebrae [21]. The SBAC permits the estimation of trabecular bone density, avoiding cortical bone, excessive bone formation (syndesmophytes, bone bridge) and vascular calcifications. The same diagnostic performance for osteoporosis screening has been seen for all the lumbar vertebrae, but L1 is the easiest identifiable [21]. Recent studies reported that an SBAC-L1 $\leq 145$ Hounsfield units (HU) was more reliable than a T-score $\leq-2.5$ SD for identifying patients at risk of VF in rheumatoid arthritis (RA) and the general population [21,22]. Furthermore, SBAC-L1 allowed us to identify $50 \%$ of sclerodermic patients with bone fragility and was statistically significantly associated with severity criteria of the disease [23]. CT scans offer an opportunity to explore the trabecular bone density in the AS population and to study the effect of vertebral ankylosis on trabecular bone density.

Our primary objective was to determine the impact of lumbar vertebral ankylosis on trabecular bone fragility through the SBAC measure for each lumbar vertebra according to their ankylosis status: ankylosed versus non-ankylosed. The secondary objective was to determine whether the presence of vertebral ankylosis on mSASSS was associated with a higher risk of reaching an SBAC under the fracture threshold $(\leq 145 \mathrm{HU})$. 


\section{Patients and methods}

\subsection{Population}

This descriptive and retrospective study was performed on AS patients followed at the Nancy University Hospital, according to the ASAS 2009 or New York-modified criteria [24,25]. To be included in this study, patients should have performed radiographs of the pelvis and cervicodorso-lumbar spines as well as a thoracic, TAP or abdomino-pelvic CT scan within a delay of two years between the two exams. The records were selected from the pre-biologic evaluation between 2009 and March 2017.

Demographic characteristics (age, gender, smoker status, etc.), clinical data (disease duration, activity score, etc.), biological data (C-reactive protein (CRP)) and treatments were collected from the complete medical record.

\subsection{AS radiographic assessment}

The radiographs were anonymized and read on Osirix software (v6.5.1-64 bits).

The frontal pelvic radiographs or radiographs from the lumbo-sacral junction were analyzed for sacroiliitis by two independent senior readers (MF, FV), with adjudication by a third rheumatologist (DL) in case of discordance, according to the modified New York classification $[24,25]$.

Sagittal spinal radiographs (cervical and lumbar) were evaluated for the presence of squaring, syndesmophytes or ankylosis (bone bridge) for anterior vertebral corners, from $\mathrm{C} 2$ inferior to $\mathrm{T} 1$ superior and from T12 inferior to S1 superior (score 1 for squaring, 2 for syndesmophytes, 3 for ankylosis), according to mSASSS score, ranging from 0 to 72 [26,27]. Structural spinal involvement was defined by an mSASSS $\geq 2$, corresponding to the presence of at least one syndesmophyte. The mSASSS was performed by three rheumatologists (MF, FV, DL). The diagnosis of syndesmophyte was considered if two of the three readers agreed. The mSASSS was calculated with the adjudication for each corner, without considering grade 1, in view of its poor reproducibility in previous studies $[28,29,30]$. Ankylosed lumbar vertebra was defined by the presence of bone bridges with its two adjacent vertebrae. Partial ankylosed vertebra was defined by the presence of a bone bridge with only one of its adjacent vertebrae. The level and number of ankylosed lumbar vertebrae were then evaluated.

\subsection{Reproducibility of the measures (mSASSS and sacroiliitis)}

Intrareader reproducibility was performed on 30 exams and interreader reproducibility on all exams between the three readers for sacroiliitis and mSASSS.

\subsection{Densitometric scanographic bone evaluation (scanographic bone attenuation coefficient of L1: SBAC-L1) (Figure 1)}

All CT scans were performed at the Nancy University Hospital and were read on OSIRIX software (v6.5.1-64 bits). A total of 73 CT scans were available: 67 TAP CT scans, 3 thoracic CT scans and 3 abdominopelvic CT scans.

The SBAC was measured on axial sections through the pedicles in the bone window for each lumbar vertebra. The largest elliptical region of interest (ROI) was drawn in the trabecular bone and provided the average bone mineral density (in HU). This evaluation was performed by only a reader (MF) because we have previously shown the excellent intra- and interreader reliability of the SBAC-L1 (kappa > 0.9) [23]. Pickardt et al. showed that CT scans performed similarly from $\mathrm{T} 12$ to $\mathrm{L} 5$ for the SBAC measure [21]. 
A threshold of $145 \mathrm{HU}$ was used because it identified $96.6 \%$ of the patients with VF in a general population, whereas the DXA (with T-score $\leq-2.5 \mathrm{SD}$ ) identified only $39 \%$ of the patients with VF in the same population [21]. This threshold of $145 \mathrm{HU}$ was used to maintain an acceptable balance between sensitivity and specificity in this population, in which a higher risk of bone fragility is suspected.

\subsection{Ethics approval}

All of the data used were obtained from the medical records. No supplementary examination was performed for patients to meet the inclusion criteria. This study is registered to the Information Technology and Freedoms Commission for the University Hospital of Nancy (file number: 2019PI007) and was designed in accordance with the general ethical principles outlined in the Declaration of Helsinki. The protocol of this study was approved by the Information Technology and Freedoms Commission. All patients gave their consent for the use of their medical data during the time period they received medical care at the University Hospital.

\subsection{Statistical analysis}

Both descriptive and comparative analyses were conducted by accounting for the nature and distribution of the variables. Qualitative variables were described as frequencies and percentages; quantitative variables were evaluated with the mean \pm standard deviation (SD) or with the median and interquartile range (IQR). For quantitative variables, Student's t test or the Mann-Whitney U test were used. For qualitative variables, the chi-squared test was used, along with Fisher's exact test if necessary. The association between the trabecular bone density of each lumbar vertebra (L1 to L5), measured by the SBAC, and structural spinal involvement was analyzed by logistic binary regression with the odds ratio (OR) and its $95 \%$ confidence interval $(95 \% \mathrm{CI})$. The Kruskal-Wallis test was performed to study the relationship between the SBAC of the lumbar vertebra and the ankylosed status.

To analyze the intrareader and interreader reliabilities, we used Cohen's kappa method. The risk $\alpha$ was established as 0.05 . IBM ${ }^{\mathrm{TM}}$ SPSS Statistics v23 was used for the data analysis. 


\section{Results}

\subsection{Population}

Of 1503 spondyloarthritis patients followed between 2009 and 2017 and screened for biologic treatment initiation, 73 patients fulfilled the inclusion criteria. The mean age was 60.3 years $(+/-10.7)$, with a large predominance of men $(89 \%)$. The disease duration was 24.6 years $(+/-$ $24)$, and the mean BASDAI, BASFI and ASDAS were $7.2(+/-10.5), 43.5(+/-23.7)$ and $3.4(+/-$ $1.2)$, respectively. Patients were mainly treated with TNF-blockers (58.9\% of the patients), and NSAIDs $(67.1 \%$ of the patients). A total of $9.6 \%$ took corticosteroids (Table 1). The mean duration between radiographs and CT scans was 75.6 days $( \pm 166.4)$.

Concerning osteoporosis screening, 53 patients $(72.6 \%)$ had at least one clinical or biological risk factor for osteoporosis. Sixteen $(21.9 \%)$ underwent spine DXA during their follow-up. Among them, five patients had osteoporosis on DXA when the 3 sites (spine, total hip and femoral neck) were taken into account. VFs were depicted in 9 patients on radiographs. DXA images were available for three of them. One patient presented osteoporosis (T-score: -2.7 SD), another patient was classified with osteopenia (T-score: -1.9 SD), and the last one had a normal T-score (+0.6 SD). Among the 73 patients, 11 (15.1\%), $16(21.9 \%)$ and 12 (16.4\%) took calcium tablets, vitamin D supplementation and specific anti-osteoporotic drugs, respectively. The anti-osteoporotic treatments were bisphosphonates (10/12: zoledronic acid, alendronate, risedronate, pamidronate), denosumab (1/12) and strontium renalate (1/12).

\subsection{AS radiographic assessment (Figure 2)}

All patients presented sacroiliitis on radiographs. The kappa coefficients were 0.71 (95\% CI: $0.49-0.89)$ and 0.82 (95\% CI: 0.7-0.93) for the right sacroiliac joint and 0.54 (95\% CI: 0.30 $0.75)$ and 0.69 (95\% CI: 0.55-0.82) for the left sacroiliac joint, for inter- and intrareader reproducibility, respectively.

Concerning spinal involvement, the cervical spine assessment was technically limited by spine deformity and ankylosis. Indeed, an optimal assessment of this segment was obtained for 79.5\% of the patients. Fourteen patients (19.2\%) had no spinal lesions. The mean mSASSS was 20.7 $( \pm 21.3)$, and 60 patients $(82.2 \%)$ presented an mSASSS $\geq 2$. Thirty-seven patients $(50.7 \%)$ had at least one bone bridge on the spine, and six patients $(8.2 \%)$ had a bamboo spine. For the lumbar segment, $17(23.3 \%)$ and $13(17.8 \%)$ patients had complete or partial vertebral ankylosis, respectively. The intra- and interreader reproducibility for spinal structural involvement was excellent. For the mSASSS, the kappa coefficients were 0.97 (95\% CI: 0.930.98 ) and 0.97 (95\% CI: 0.95-0.98) for intra- and interreader, respectively. Adjudication resulted in the reclassification of three patients in the mSASSS- group.

\subsection{Densitometric scanographic bone evaluation of lumbar vertebrae (SBAC)}

Two patients had no available evaluation at L2, L3, L4 and L5 levels, one at L5 vertebra and one at L1 vertebra, due to severe spine deformation. All four patients were in the mSASSS+ group. The mean SBAC was 141.1 HU $( \pm 45)$ for L1, $130.4 \mathrm{HU}( \pm 52.9)$ for L2, $127.9 \mathrm{HU}$ $( \pm 52.2)$ for $\mathrm{L} 3,124.3 \mathrm{HU}( \pm 58.2)$ for L4 and $135 \mathrm{HU}( \pm 56.7)$ for L5. There was not significant difference between the mean SBAC for each lumbar vertebra between patients with or without vertebral fractures ( $p$ non-significant); 7 of the 9 patients with VF have a SBAC for most lumbar vertebrae under the fracture threshold. We found no statistically significant association between SBAC from L1 to L5 and mSASSS status. However, there was a significant difference in SBAC values between patients with bone bridges versus patients without bone bridges $(p<0.01)$. 
Compared to patients without bone bridges, patients with bone bridges of the lumbar vertebrae more frequently presented an SBAC under the fracture threshold of $145 \mathrm{HU}$ (for each lumbar vertebra) $(\mathrm{p}<0.05)$. Thirty-four patients $(91.9 \%)$ with bone bridges on mSASSS presented an SBAC under the fracture threshold for one of the five lumbar vertebrae (Table 2). We did not find any correlation between the bone mineral density or T-score and the SBAC for each lumbar vertebra.

\subsection{Association between SBAC of the lumbar vertebra and ankylosed status}

The mean lumbar SBAC progressively decreased according to the degree of lumbar vertebra ankylosis from $150.5 \mathrm{HU}( \pm 44.9)$ in non-ankylosed vertebrae to $137.9 \mathrm{HU}( \pm 44.7)$ for partial ankylosed vertebrae $(\mathrm{p}<0.05)$ and $79.3 \mathrm{HU}( \pm 43.9)$ in ankylosed vertebrae $(\mathrm{p}<0.001)$. Seventeen (23.3\%) and $13(17.8 \%)$ patients had at least one lumbar vertebra with complete or partial ankylosis, respectively. Complete ankylosis of the lumbar vertebra was associated with an increased risk of SBAC under the fracture threshold (OR $=4.95 ; 95 \% \mathrm{CI}: 1.10-17.36)$. For partial ankylosis of the lumbar vertebrae, only the L3 and L4 vertebrae were associated with this risk (OR $=11.8$ (95\% CI:1.82-25.67) and 15 (95\% CI:2.54-30.85)), respectively. (Table 3 and Figure 2) 


\section{Discussion}

This study is the first to show that severe spinal involvement, such as bone bridges in cervical or lumbar spine segments on mSASSS is associated with lower lumbar SBAC values. More precisely, local partial and complete ankylosis of any lumbar vertebra were associated with lower values of lumbar SBAC (L1 to L5), suggesting deterioration of the trabecular bone density in AS. In our AS patients, nearly $60 \%$ presented bone fragility with an SBAC $\leq 145 \mathrm{HU}$.

The population of this study was similar to other AS populations, such as the OASIS or GESPIC cohorts [31]. Our patients were more frequently treated with TNF-blockers (58.9\%), but NSAID intake was similar to that of other cohorts (approximately 67\%). In the OASIS cohort, $19 \%$ of the patients were mSASSS- [32], which was similar to our population (with $18.7 \%$ of mSASSS-). However, the mean mSASSS was higher (20.7) in our population than in the OASIS cohort (10.8), probably because our study included older patients with a longer disease duration [32]. We have also shown that osteoporosis screening is not automatically performed in routine care, despite the recommendations of French Society for Rheumatology (SFR) about the screening and management of comorbidities, including osteoporosis in spondyloarthritis patients [33]. In our patients, only $22 \%$ had undergone DXA, whereas more than $72 \%$ of them had at least one clinical or biological risk factor for osteoporosis. One of the limits of this study was the low number of DXA performed in our population. We did not find any correlation between the bone mineral density or T-score and the SBAC for each lumbar vertebra. Due to the low number of DXA, we are not able to conclude about this correlation. All of the patients with osteoporosis or low BMD (osteopenia) on DXA have a SBAC for each lumbar vertebra under the fracture threshold of $145 \mathrm{HU}$. Some studies showed an interest in the use of trabecular bone score (TBS), not influenced by syndesmophytes and correlated to lumbar BMD [19,34].

The mSASSS evaluates spinal damage in AS from the antero-inferior corner of $\mathrm{C} 2$ to the anterosuperior corner of $\mathrm{T} 1$ and from the antero-inferior corner of $\mathrm{T} 12$ to the antero-superior corner of S1 [26,27]. In our study, the cervical evaluation was technically limited due to severe ankylosis and deformation; however, $79.5 \%$ of the patients had an optimal assessment of the cervical spine. As previously reported, we obtained very good reproducibility for mSASSS with a kappa coefficient of 0.97 for intra- and interreaders [35,36,37]. Only anterior vertebral corners were evaluated with the mSASSS. The posterior segment of the spine was not evaluated; however, various studies have shown that 20 to $50 \%$ of AS patients had facet joint ankylosis in the cervical and/or lumbar spine associated with anterior spinal involvement $[38,39]$. On radiographs, posterior ankylosis assessment is difficult due to the two-dimensional projection of the lumbar facet joints. In our study, we were not able to compare patients with isolated cervical or lumbar bone bridges due to the small number in each group (only 7 patients with isolated cervical bone bridges and 9 with isolated lumbar bone bridges).

We did not show any association between SBAC and mSASSS. This could be explained by the fact that mSASSS is a composite score assessing different structural damages: squaring, erosion, syndesmophyte and bone bridge, reflecting different levels of structural severity. Squaring and erosion were excluded from our analysis due to poor intra- and interreader reliabilities, as previously mentioned in the literature [28,29,30]. In this study, we showed that SBAC significantly decreased when vertebrae presented at least one bone bridge in the cervical 
or lumbar spine. Moreover, when we studied the local interaction between the degree of lumbar vertebra mobility and the lumbar SBAC (L1-L5) values, AS patients with at least one bone bridge presented a statistically significant risk of having an SBAC under the fracture threshold compared to AS patients with no ankylosis or only syndesmophytes without bone bridges. Our study did not respond to a potential deleterious effect of syndesmophytes on SBAC since the number of patients without spinal lesions was too low $(n=14)$.

The use of SBAC is interesting in AS patients because this technique permits direct evaluation of the trabecular bone density, avoiding cortical artifacts, such as osteophytes and syndesmophytes, as well as other artifacts (vascular calcifications) frequently observed in elderly AS patients. Furthermore, the SBAC measure is very reproducible $[23,40]$ and easy to perform. This method could be used in daily practice to consider initial opportunistic bone screening on CT scans already performed during AS patients' follow-up (treatment side effects, comorbidity evaluation, emergency, etc.). The SBAC was not available for four patients. Among these four patients, SBAC of L2, L3, L4 and L5 levels were not available for two patients, SBAC of L1 for one patient and SBAC of L5 for another patient because spinal deformation made the measurement impossible in the region of interest. For these patients, the SBAC evaluation was performed on the available vertebrae. All of these patients were in the mSASSS+ group.

This study is the first to evaluate the consequence of spinal ankylosis on trabecular bone density using opportunistic CT scans in AS patients. Complete ankylosis of the lumbar vertebra and partial ankylosis of L3 and L4 were associated with lower values of SBAC, suggesting deterioration of the trabecular bone structure in ankylosed vertebrae. The deterioration of trabecular bone attenuation could be explained by a loss of mechanical strain related to ankylosis (partial or total). Indeed, we know that mechanical strain on the bone increases its density, as in physical activity $[41,42,43,44]$. Moreover, bone ankylosis may also reflect patients with a more severe disease and more biological inflammation [45], resulting in less physical activity and mobility. Local or systemic inflammation could also increase spinal bone loss. This hypothesis may be suggested in our population since patients with bone bridges had more severe disease activity measured by the ASDAS. This study raises questions about the sensitivity to changes in SBAC over time and the effect of biologic treatments and antiosteoporotic drugs on trabecular bone mineralization. Further longitudinal studies are needed to answer these questions.

In conclusion, we showed that $\mathrm{CT}$ scans is an alternative exam for screening bone fragility (through the SBAC of each lumbar vertebrae) in AS patients. The SBAC measure is highly reproducible and can be easily performed in daily practice on opportunistic CT scans (performed for any other indication). We showed that patients with bone bridges on mSASSS (cervical or lumbar segments) and patients with lumbar ankylosis (total or partial) had a higher risk of presenting an SBAC under the fracture threshold. Patients with spinal ankylosis should be screened for osteoporosis, regardless of other osteoporosis risk factors, using opportunistic CT scans and DXA (the gold standard). The bone loss kinetics and structural progression should also be investigated in further longitudinal studies. 


\section{Declarations}

\section{Ethics approval and consent to participate}

All of the data used were obtained from medical records. No examinations were performed for patients to meet the inclusion criteria.

This study is registered to the Information Technology and Freedoms Commission for the University Hospital of Nancy (file number: 2019PI007) and was designed in accordance with the general ethical principles outlined in the Declaration of Helsinki. The protocol of this study was approved by the Information Technology and Freedoms Commission for the University Hospital of Nancy. All patients gave consent for the use of their medical data during the time period they received medical care at the University Hospital.

\section{Availability of data and material}

Data are available upon reasonable request.

\section{Competing interest}

All of the authors declare that they have no conflicts of interest.

\section{Acknowledgments}

This research did not receive any specific grant from funding agencies in the public, commercial, or not-for-profit sectors.

\section{Funding}

None

\section{Authors' contributions}

All authors meet the journal's criteria for authorship and have made substantial contributions to all of the following: (1) conception and design of the study, acquisition of data, or analysis and interpretation of data; (2) drafting the article or critical revision for important intellectual content; and (3) final approval of the version to be submitted.

\section{Submission declaration}

This work has not been published previously, it is not under consideration for publication elsewhere, this publication is approved by all authors and tacitly or explicitly by the responsible authorities where the work was carried out, and, if accepted, it will not be published elsewhere in the same form, in English or in other language, including electronically without the written consent of the copyright-holder. 


\section{References}

${ }^{1}$ González-Chávez SA, Quiñonez-Flores CM, Pacheco-Tena C. Molecular mechanisms of bone formation in spondyloarthritis. Joint Bone Spine. 2016;83(4):394-400.

${ }^{2}$ Wendling D, Claudepierre P. New bone formation in axial spondyloarthritis. Joint Bone Spine. 2013;80(5):454-8.

${ }^{3}$ El Maghraoui A. Extra-articular manifestations of ankylosing spondylitis: prevalence, characteristics and therapeutic implications. Eur J Intern Med. 2011;22(6):554-60.

${ }^{4}$ Ramírez J, Nieto-González JC, Curbelo Rodríguez R, Castañeda S, Carmona L. Prevalence and risk factors for osteoporosis and fractures in axial spondyloarthritis: A systematic review and meta-analysis. Semin Arthritis Rheum. 2018;48(1):44-52

${ }^{5}$ van der Weijden M a. C, Claushuis T a. M, Nazari T, Lems WF, Dijkmans B a. C, van der HorstBruinsma IE. High prevalence of low bone mineral density in patients within 10 years of onset of ankylosing spondylitis: a systematic review. Clin Rheumatol. 2012;31(11):1529-35.

${ }^{6}$ Ghozlani I, Ghazi M, Nouijai A, et al. Prevalence and risk factors of osteoporosis and vertebral fractures in patients with ankylosing spondylitis. Bone. 2009;44(5):772-6.

${ }^{7}$ Briot K, Durnez A, Paternotte S, Miceli-Richard C, Dougados M, Roux C. Bone oedema on MRI is highly associated with low bone mineral density in patients with early inflammatory back pain: results from the DESIR cohort. Ann Rheum Dis. 2013;72(12):1914-9.

${ }^{8}$ Schett G. Joint remodelling in inflammatory disease. Ann Rheum Dis. 2007;66 Suppl 3:iii42-44.

${ }^{9}$ Ardizzone M, Javier RM, Kuntz JL. [Ankylosing spondylitis and osteoporosis]. Rev Med Interne. 2006;27(5):392-9.

${ }^{10}$ Klingberg E, Lorentzon M, Mellström D, et al. Osteoporosis in ankylosing spondylitis - prevalence, risk factors and methods of assessment. Arthritis Res Ther. 2012;14(3):R108.

${ }^{11}$ Fechtenbaum M, Molto A, Roux C, Goupille P, Chevret S, Briot K. Baseline MRI inflammation is not a determinant of 5-year bone mineral density loss in patients with early spondyloarthritis. Joint Bone Spine. 2020;87(1):63-8.

${ }^{12}$ Klingberg E, Lorentzon M, Göthlin J, et al. Bone microarchitecture in ankylosing spondylitis and the association with bone mineral density, fractures, and syndesmophytes. Arthritis Res Ther. 2013;15(6):R179.

${ }^{13}$ Pray C, Feroz NI, Nigil Haroon N. Bone Mineral Density and Fracture Risk in Ankylosing Spondylitis: A Meta-Analysis. Calcif Tissue Int. 2017;101(2):182-92.

${ }^{14}$ Klingberg E, Geijer M, Göthlin J, et al. Vertebral fractures in ankylosing spondylitis are associated with lower bone mineral density in both central and peripheral skeleton. $\mathrm{J}$ Rheumatol. 2012;39(10):1987-95.

${ }^{15}$ Ghozlani I, Ghazi M, Nouijai A, et al. Prevalence and risk factors of osteoporosis and vertebral fractures in patients with ankylosing spondylitis. Bone. 2009;44(5):772-6.

${ }^{16}$ Geusens P, De Winter L, Quaden D, et al. The prevalence of vertebral fractures in spondyloarthritis: relation to disease characteristics, bone mineral density, syndesmophytes and history of back pain and trauma. Arthritis Res Ther. 2015;17:294

${ }^{17}$ Deminger A, Klingberg E, Lorentzon M, et al. Which measuring site in ankylosing spondylitis is best to detect bone loss and what predicts the decline: results from a 5-year prospective study. Arthritis Res Ther. 2017;19(1):273.

${ }^{18}$ Malochet-Guinamand S, Pereira B, Tatar Z, et al. Prevalence and risk factors of low bone mineral density in spondyloarthritis and prevalence of vertebral fractures. BMC Musculoskelet Disord. 2017;18(1):357.

${ }^{19}$ Wildberger L, Boyadzhieva V, Hans D, Stoilov N, Rashkov R, Aubry-Rozier B. Impact of lumbar syndesmophyte on bone health as assessed by bone density (BMD) and bone texture (TBS) in men with axial spondyloarthritis. Joint Bone Spine. 2017;84(4):463-6.

${ }^{20}$ Magrey MN, Lewis S, Asim Khan M. Utility of DXA scanning and risk factors for osteoporosis in ankylosing spondylitis-A prospective study. Semin Arthritis Rheum. 2016;46(1):88-94. 
${ }^{21}$ Pickhardt PJ, Pooler BD, Lauder T, del Rio AM, Bruce RJ, Binkley N. Opportunistic screening for osteoporosis using abdominal computed tomography scans obtained for other indications. Ann Intern Med. 2013;158(8):588-95.

${ }^{22}$ Perrier-Cornet J, Omorou AY, Fauny M, Loeuille D, Chary-Valckenaere I. Opportunistic screening for osteoporosis using thoraco-abdomino-pelvic CT-scan assessing the vertebral density in rheumatoid arthritis patients. Osteoporos Int. 2019;30(6):1215-22.

${ }^{23}$ Fauny M, Bauer E, Albuisson E, et al. Vertebral fracture prevalence and measurement of the scanographic bone attenuation coefficient on CT-scan in patients with systemic sclerosis. Rheumatol Int. 2018;38(10):1901-10.

${ }^{24}$ van der Linden S, Valkenburg HA, Cats A. Evaluation of diagnostic criteria for ankylosing spondylitis. A proposal for modification of the New York criteria. Arthritis Rheum. 1984;27(4):361-8.

${ }^{25}$ Goie The HS, Steven MM, van der Linden SM, Cats A. Evaluation of diagnostic criteria for ankylosing spondylitis: a comparison of the Rome, New York and modified New York criteria in patients with a positive clinical history screening test for ankylosing spondylitis. Br J Rheumatol. 1985;24(3):242-9.

${ }^{26}$ Creemers MCW, Franssen MJ a. M, van't Hof MA, Gribnau FWJ, van de Putte LBA, van Riel PLCM. Assessment of outcome in ankylosing spondylitis: an extended radiographic scoring system. Ann Rheum Dis. 2005;64(1):127-9.

${ }^{27}$ Wanders AJB, Landewé RBM, Spoorenberg A, et al. What is the most appropriate radiologic scoring method for ankylosing spondylitis? A comparison of the available methods based on the Outcome Measures in Rheumatology Clinical Trials filter. Arthritis Rheum. 2004;50(8):2622-32.

${ }^{28}$ Baraliakos X, Listing J, Rudwaleit M, et al. Progression of radiographic damage in patients with ankylosing spondylitis: defining the central role of syndesmophytes. Ann Rheum Dis. 2007;66(7):9105 .

${ }^{29}$ Baraliakos X, Listing J, Rudwaleit M, Sieper J, Braun J. Development of a radiographic scoring tool for ankylosing spondylitis only based on bone formation: Addition of the thoracic spine improves sensitivity to change. Arthritis Care \& Research. 2009;61(6):764-71.

${ }^{30} \mathrm{Kim}$ T-J, Kim H-S, Joo K-B, Kim S, Kim T-H. Do we really need to evaluate entire cervical spines for squaring score in modified stoke ankylosing spondylitis spinal score? J Rheumatol. 2008;35(3):477 -9 .

${ }^{31}$ Protopopov M, Sieper J, Haibel H, Listing J, Rudwaleit M, Poddubnyy D. Relevance of structural damage in the sacroiliac joints for the functional status and spinal mobility in patients with axial spondyloarthritis: results from the German Spondyloarthritis Inception Cohort. Arthritis Res Ther. 2017;19(1):240.

${ }^{32}$ Ramiro S, van der Heijde D, van Tubergen A, et al. Higher disease activity leads to more structural damage in the spine in ankylosing spondylitis: 12-year longitudinal data from the OASIS cohort. Ann Rheum Dis. 2014;73(8):1455-61.

${ }^{33}$ Wendling D, Lukas C, Prati C, Claudepierre P, Gossec L, Goupille P, et al. 2018 update of French Society for Rheumatology (SFR) recommendations about the everyday management of patients with spondyloarthritis. Joint Bone Spine. 2018;85(3):275-84.

${ }^{34}$ Boussoualim K, Amouzougan A, Pallot-Prades B, Denarié D, Collet P, Marotte H, et al. Evaluation of bone quality with trabecular bone score in active spondyloarthritis. Joint Bone Spine.

2018;85(6):727-31.

${ }^{35}$ Claudepierre P, de Hooge MSM, Feydy A, et al. Reliability of mSASSS scoring in everyday practice in DESIR-cohort study centres: cross-sectional study of agreement with trained readers. Ann Rheum Dis. 2016;75(12):2213-4.

${ }^{36}$ Biagioni BJ, Gladman DD, Cook RJ, et al. Reliability of radiographic scoring methods in axial psoriatic arthritis. Arthritis Care Res (Hoboken). 2014;66(9):1417-22.

${ }^{37}$ Salaffi F, Carotti M, Garofalo G, Giuseppetti GM, Grassi W. Radiological scoring methods for ankylosing spondylitis: a comparison between the Bath Ankylosing Spondylitis Radiology Index and the modified Stoke Ankylosing Spondylitis Spine Score. Clin Exp Rheumatol. 2007;25(1):67-74. 
${ }^{38}$ Maas F, Arends S, Brouwer E, et al. Incorporating assessment of the cervical facet joints in the modified Stoke ankylosing spondylitis spine score is of additional value in the evaluation of spinal radiographic outcome in ankylosing spondylitis. Arthritis Res Ther. 2017;19(1):77.

${ }^{39}$ Maas F, Spoorenberg A, Brouwer E, et al. Radiographic damage and progression of the cervical spine in ankylosing spondylitis patients treated with TNF- $\alpha$ inhibitors: Facet joints vs. vertebral bodies. Semin Arthritis Rheum. 2017;46(5):562-8.

${ }^{40}$ Fauny M, Albuisson E, Bauer E, Perrier-Cornet J, Chary-Valckenaere I, Loeuille D. Study of vertebral fracture and Scanographic Bone Attenuation Coefficient in rheumatoid arthritis and ankylosing spondylitis vs. controls. Sci Rep. 2019;9(1):13323.

${ }^{41}$ Moreira LDF, Oliveira ML de, Lirani-Galvão AP, Marin-Mio RV, Santos RN dos, Lazaretti-Castro M. Physical exercise and osteoporosis: effects of different types of exercises on bone and physical function of postmenopausal women. Arq Bras Endocrinol Metabol. 2014;58(5):514-22.

${ }^{42}$ Birge SJ, Dalsky G. The role of exercise in preventing osteoporosis. Public Health Rep. 1989;104(Suppl):54-8.

${ }^{43}$ Kannus P, Sievänen H, Vuori I. Physical loading, exercise, and bone. Bone. 1996;18(1 Suppl):1S-3S.

${ }^{44}$ Pfeifer M, Sinaki M, Geusens P, et al. Musculoskeletal rehabilitation in osteoporosis: a review. J Bone Miner Res. 2004;19(8):1208-14.

${ }^{45}$ Aouad K, Ziade N, Baraliakos X. Structural progression in axial spondyloarthritis. Joint Bone Spine. 2020;87(2):131-6. 
Table 1: Demographical and clinical characteristics of the 73 AS patients according to the mSASSS (mSASSS $+/$ mSASSS -) and bone bridge status

\begin{tabular}{|c|c|c|c|c|c|c|c|c|}
\hline & & $\begin{array}{c}\text { Total } \\
\text { population } \\
\mathrm{n}=73\end{array}$ & $\begin{array}{c}\text { mSASSS + } \\
\mathrm{n}=60\end{array}$ & $\begin{array}{c}\text { mSASSS - } \\
\mathrm{n}=13 \\
\end{array}$ & $\mathrm{p}$ & $\begin{array}{c}\text { Bone } \\
\text { bridge }+ \\
\mathrm{n}=37\end{array}$ & $\begin{array}{c}\text { Bone } \\
\text { bridge - } \\
\mathrm{n}=23 \\
\end{array}$ & $\mathrm{p}$ \\
\hline \multirow[t]{4}{*}{ Demographic and c } & Age $(n=73)$ & $60.3(60)$ & $62(61)$ & $52.7(57)$ & NS & $62(57.5-73)$ & $59(53-67)$ & NS \\
\hline & $\operatorname{Men}(n=73)$ & $65(89)$ & $53(88.3)$ & $12(92.3)$ & NS & 34 (91.9) & $19(82.6)$ & NS \\
\hline & Smoker $(n=48)$ & $31(42.5)$ & $25(41.7)$ & $6(46.2)$ & NS & $17(45.9)$ & $8(34.8)$ & NS \\
\hline & Alcohol intake $(n=28)$ & $4(5.5)$ & $4(6.7)$ & $0(0)$ & NS & $4(10.8)$ & $0(0)$ & NS \\
\hline \multirow[t]{7}{*}{ AS characteristics } & Disease duration $(\mathrm{n}=71)$ & $24(12-34)$ & $25(13-35)$ & $\begin{array}{c}15.5(12- \\
25.3)\end{array}$ & NS & $\begin{array}{c}27(13.8- \\
35.8)\end{array}$ & $24(11-35)$ & NS \\
\hline & BASFI $(n=58)$ & $43.5(23.7)$ & $44.5(22.2)$ & $41.2(30.8)$ & NS & $46.7(22.2)$ & $42(22.4)$ & NS \\
\hline & BASDAI $(n=62)$ & $7.2(10.5)$ & $7.1(10.5)$ & $8.4(11.3)$ & NS & $7.2(12.7)$ & $6.9(7.3)$ & NS \\
\hline & $\operatorname{ASDAS}(n=21)$ & $3.4(1.2)$ & $3.4(0.9)$ & $3(2.6)$ & NS & $3.7(1)$ & $2.81(0.6)$ & $<0.05$ \\
\hline & HLA B27 $(n=69)$ & $46(63)$ & $39(65)$ & $7(53.8)$ & NS & $26(70.3)$ & $13(56.5)$ & NS \\
\hline & $\mathrm{CRP}(\mathrm{n}=69)$ & $31(42.5)$ & $28(46.7)$ & $3(23.1)$ & NS & $18(48.6)$ & $10(43.5)$ & NS \\
\hline & mSASSS $(n=73)$ & $20.7(21.2)$ & $25.1(20.8)$ & $0(0)$ & 0.0001 & $37.2(17.8)$ & $5.9(4.2)$ & 0.0001 \\
\hline \multicolumn{2}{|c|}{ Mean grade of left sacroiliitis $(n=73)$} & $3.3(0.8)$ & & & & & & \\
\hline \multicolumn{2}{|c|}{ Mean grade of right sacroiliitis $(n=73)$} & $3.4(0.6)$ & & & & & & \\
\hline \multirow[t]{2}{*}{ Treatments } & Corticosteroids $(n=49)$ & $7(9.6)$ & $5(8.3)$ & $2(15.4)$ & NS & $3(8.1)$ & $2(8.7)$ & NS \\
\hline & NSAIDs $(n=51)$ & $49(67.1)$ & $44(73.3)$ & $5(38.5)$ & NS & $30(81.1)$ & $14(60.9)$ & 0.05 \\
\hline \multicolumn{2}{|c|}{ PPI Proton Pump Inhibitor $(\mathrm{n}=15)$} & $15(20.5)$ & $14(23.3)$ & $1(7.7)$ & / & $9(24.3)$ & $5(21.7)$ & / \\
\hline & TNF-blockers $(n=43)$ & $43(58.9)$ & $36(60)$ & $7(53.8)$ & l & $23(62.2)$ & $13(56.5)$ & l \\
\hline \multirow[t]{3}{*}{ Osteoporosis } & $\geq 1$ risk factor $(\mathrm{n}=73)$ & $53(72.6)$ & $46(76.7)$ & $7(53.8)$ & NS & $29(78.4)$ & $17(73.9)$ & NS \\
\hline & $\mathrm{D}$ and/or calcium $(\mathrm{n}=73)$ & $18(24.6)$ & $14(23.3)$ & $4(30.8)$ & NS & $9(24.3)$ & $5(21.7)$ & NS \\
\hline & -osteoporotic drug $(\mathrm{n}=72)$ & $12(16.4)$ & $9(15)$ & $3(23.1)$ & NS & $8(21.6)$ & $1(4.3)$ & NS \\
\hline
\end{tabular}

AS: ankylosing spondylitis, ASDAS: Ankylosing Spondylitis Disease Activity Score, BASDAI: Bath ankylosing spondylitis disease activity index, BASFI: Bath ankylosing spondylitis functional index, CRP: C-reactive protein, mSASSS: modified Stoke Ankylosing Spondylitis Spinal Score, NS: non-significant, NSAIDs: Non-steroidal anti-inflammatory drugs, TNF: tumor necrosis factor

Age in the mSASSS+ group and disease duration are the median (IQR), whereas age in the general population, BASDAI, BASFI, and ASDAS are the mean $( \pm \mathrm{SD})$. In the comparisons, Student's t-test or the Mann-Whitney U test were used. For qualitative variables, the chi-square test with, if necessary, the exact calculation of Fisher was used. The risk $\alpha$ was established as 0.05 
Table 2: Scanographic bone evaluation of the lumbar spine according to the mSASSS and bone bridge status.

\begin{tabular}{|c|c|c|c|c|c|c|c|}
\hline & $\begin{array}{c}\text { Total } \\
\text { population } \\
\mathrm{N}=73 \\
\end{array}$ & $\begin{array}{c}\text { mSASSS + } \\
\mathrm{N}=60\end{array}$ & $\begin{array}{c}\text { mSASSS - } \\
\mathrm{N}=13\end{array}$ & $\mathbf{P}$ & $\begin{array}{c}\text { Bone bridge } \\
+\mathrm{N}=37\end{array}$ & $\begin{array}{c}\text { Bone bridge } \\
- \\
\mathrm{N}=23 \\
\end{array}$ & $\mathbf{P}$ \\
\hline SBAC-L1 & $141.1(45)$ & $138.1(44.8)$ & $154.8(44.9)$ & NS & $123.9(41.1)$ & $160.4(41.9)$ & $<0.01$ \\
\hline$\leq 145 \mathrm{HU}$ & $42(57.5)$ & $36(60)$ & $6(46.2)$ & NS & $27(73)$ & $9(39.1)$ & $<0.01$ \\
\hline SBAC-L2 & $130.4(52.9)$ & $127.2(55.1)$ & $144.5(41.1)$ & NS & $111.5(48.8)$ & $149.8(50.5)$ & $<0.01$ \\
\hline$\leq 145 \mathrm{HU}$ & $42(57.5)$ & $35(58.3)$ & $7(53.8)$ & NS & $26(70.3)$ & $9(39.1)$ & $<0.05$ \\
\hline SBAC-L3 & $127.9(52.2)$ & $124.9(54.4)$ & $141.3(39.9)$ & NS & $105.2(53.1)$ & $151.3(40.1)$ & $<0.001$ \\
\hline$\leq 145 \mathrm{HU}$ & $47(64.4)$ & $39(65)$ & $8(61.5)$ & NS & $29(78.4)$ & $10(43.5)$ & $<0.01$ \\
\hline SBAC-L4 & $124.3(58.2)$ & $119.7(61.2)$ & $145(38.8)$ & NS & $99.7(61.2)$ & $152.5(41.1)$ & $<0.001$ \\
\hline$\leq 145 \mathrm{HU}$ & 45 (61.6) & 37 (61.7) & $8(61.5)$ & NS & $27(73)$ & $10(43.5)$ & $<0.05$ \\
\hline SBAC-L5 & $135(56.7)$ & $132.1(59.4)$ & $147.8(42.3)$ & NS & $106.6(51.7)$ & $163.4(46.8)$ & $<0.001$ \\
\hline$\leq 145 \mathrm{HU}$ & $40(54.8)$ & $34(56.7)$ & $6(46.2)$ & NS & $29(78.4)$ & $5(21.7)$ & $<0.001$ \\
\hline
\end{tabular}

HU: Hounsfield unit; mSASSS: modified Stoke Ankylosing Spondylitis Spinal Score; NS: non-significant; SBAC: scanographic bone attenuation coefficient

SBAC values expressed as the mean (SD), threshold $\leq 145 \mathrm{HU}$ in $\mathrm{n}(\%)$ 
Table 3: Number and percentage of lumbar vertebrae with an $\mathrm{SBAC} \leq 145 \mathrm{HU}$ according to structural involvement (syndesmophytes, partial or total ankylosis)

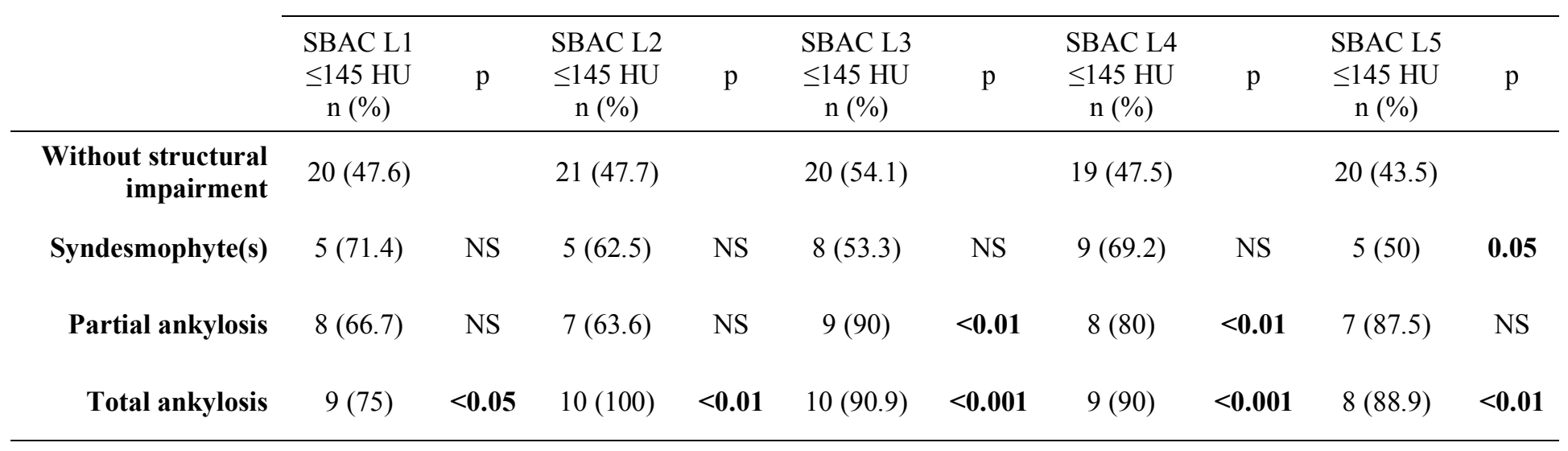

HU: Hounsfield units. L1/L2/L3/L4/L5: first/second/third/fourth/fifth lumbar vertebra. NS: non-significant. SBAC: scanographic bone attenuation coefficient. SD: standard deviation 


\section{Figure legends}

Figure 1: SBAC-L1 measurement on normal spines (A), spines with syndesmophytes (B) and ankylosed spines (C)

(sagittal lumbar spine radiographs and CT scan in the bone window and axial CT scan section of L1 with SBAC-L1 measured on the ROI)

Figure 2: SBAC of the lumbar vertebrae according to their structural involvement 